\title{
Comparison between linear evaluation and fractal geometry of the human and sheep heart
}

\author{
DELGOBO, M., OLCHANHESKI JUNIOR, L. R. and FAVERO, G. M.*
}

\author{
Laboratory of Anatomy, State University of Ponta Grossa - UEPG, CEP 84030-900, Ponta Grossa, PR, Brazil \\ *E-mail: gmfavero@uepg.br
}

\begin{abstract}
Introduction: The comparison between the anatomical heart sheep and the human heart in a straight line shows a high degree of similarity; the dimensions of the heart sheep closely resemble the human heart. Materials and Methods: All analyzes and photographs taken from the sheep heart and human heart were performed in the laboratory of human anatomy, department of health and biological sciences, State University of Ponta Grossa. The morphometric analysis included 8 specimens heart study material pertaining to the anatomy lab UEPG. The sheep hearts were obtained from slaughterhouse taking into account the relative weight next to the human, between 60 and $70 \mathrm{~kg}$. Measurements were taken with digital calipers. Results: Internally it is possible to observe the macroscopic similarity between the atrial ventricular chambers of the sheep heart and the human heart. In a non-linear analysis, it can be concluded that they are distinct in complexity, as the human heart shown largest value of fractal dimension in relation to the sheep heart. Conclusion: The comparative study suggests more comprehensive use of the sheep heart as a model for anatomical study, due to its proximity to the human heart, but denotes the differences in complexity between the organs through the use of fractal dimension.
\end{abstract}

Keywords: heart anatomy, fractal geometry, non-linear morphology.

\section{Introduction}

\subsection{The linear heart}

The heart, in a simple linear analysis, is a modified vessel, which is composed by the same layers: endothelium - endocardium, tunica media - myocardium, tunica adventitia- pericardium, and in its interior divided into four chambers, two upper and two lower. The first layer, Epicardium, comprised of a serous membrane, presents blood and lymphatic capillaries, together with nerve fibers. The intermediate layer, Myocardium, presents a cardiac muscle tissue in an organized fashion that the contraction of the muscle bundles results in compression or twisting of the cardiac chambers. The variation in the thickness of the myocardium is a result of the difference in force needed to eject the blood of a given camera, and thus the thicker portion of the myocardium is the one that involves the left ventricle. The layer located internally, called endocardium, is constituted of endothelial tissue and the subendothelial layer of thick elastic and collagen fibers, which follows a continuous along the heart valves and blood vessels (JAMES, 1961). In simple terms, the cardiac chambers can be divided into right and left atrium and left and right ventricle. The wall of the atrium is coated with a modified heart muscle called the pectineus muscle, which exerts pressure to release the blood from the atrium to the ventricles. These structures are separated anatomically amongst right and left through the interatrial septum, comprised of a thin muscle layer, unlike the interventricular septum which is formed by thick muscle layer and promotes the division between the left and right ventricle. In order to maintain blood flow in unidirectional way, cardiac valves are found between the atria and ventricles, called atrioventricular valves and the seminular valves are located between the left ventricle and the ascending aorta and between the right ventricle and the stem lung. The organization of the valves prevents backflow of blood into the atrium during ventricular contraction and backflow of blood from the pulmonary trunk and the ascending aorta to the right and left ventricles respectively (JAMES, 1961). The anatomical characteristic of the human heart approaches that of several other animal species such as pigs and sheep. However, evaluations of complexity by means of nonlinear tools allow us to observe that there is great difference between their structures, which are adapted to ensure blood flow and thus the maintenance of life.

\subsection{Non-linear beart}

Many biological structures, observed in a microscopic and macroscopic scale, are constituted of complex and irregular shape, making them not possible to be described and characterized through Euclidean geometry or dimension (FUSELER, MILLETTE, DAVIS et al., 2007). However, the dimension of these structures can be described by noninteger numbers, with values between two integer topological dimensions. The corresponding non-integer number is the Fractal Dimension (D). Shortly, a fractal has two special properties; first, they are complex as is manifested in their "roughness" and second, they present some degree of selfsimilarity over the scales. (SMITH, LANGE and MARKS, 1996; FUSELER, MILLETTE, DAVIS et al., 2007). The concept of fractals provides a useful method to quantify the inherent irregularity and complexity of the phenomena, as the 
fractal dimension measures the rate of addition of structural details (ZHANG, LIU, DEAN et al., 2005; CUTTING and GARVIN, 1987). The applicability of fractal dimension in the field of morphological sciences allowed researchers to observe that the hierarchy of blood vessels presents fractal distribution, to a homogenous mesh in smaller scales whereas larger-scale presents a branched distribution in a quasi-fractal form. In neurobiology, fractal analysis has been used to describe and quantify neuronal growth (BEHAR, 2001; BERNARD, BOSSU and GAILLARD, 2001) and arborization patterns (RISTANOVIC, NEDELJKOV, STEFANOVIC et al., 2002). Particularly in cancer, it was observed that the tumor vasculature has higher fractal dimension in comparison to physiological vasculature. The complex behavior of the healthy vasculature was compared to the tumor vasculature, being qualitatively similar, but quantitatively the vessels constituting the tumor exhibit greater complexity (LORTHOIS and CASSOT, 2010). Through the analysis of fractal heart rate variability was possible to observe the physiological role of autonomous co-activation of sympathetic nervous system and the vagus nerve in the dynamic changes in heart rate (TULPPO, KIVINIEMI, HAUTALA et al., 2005). Another interesting tool used to characterize the dynamics of the systems is the Lyapunov exponent, assessing whether the system presents a chaotic behavior or not. The very application of this tool in the analysis of heart rate variability demonstrated a chaotic behavior in the dynamics of the heart rate in healthy individual. However, in pathological situations such as Congestive heart failure and Chagas disease, was observed a linearization of the heart rate dynamics, associated with the hypertrophy of the organ (GUMIERE, FURLAN, SCHWARTZ et al., 2002; OLIVEIRA, GOMES, GUIMARÃES et al., 2006).

\section{Materials and Methods}

\subsection{Macroscopic analysis}

All analyzes and photographs taken from the sheep heart and human heart were performed in the laboratory of human anatomy, department of health and biological sciences, State University of Ponta Grossa. The morphometric analysis included 8 specimens heart study material pertaining to the anatomy lab UEPG. The sheep hearts were obtained from slaughterhouse taking into account the relative weight next to the human, between 60 and $70 \mathrm{~kg}$. Measurements were taken with digital calipers.

\subsection{Fractal dimension}

In the literature, many methods are found for calculating the fractal dimension, depending on its application, nature of the sample and desired sensitivity for the method (SMITH, LANGE and MARKS, 1996). Methods based on the distance between points are mostly used, in which the accuracy of the method depends on the sample resolution (GRIZZI, RUSSO, COLOMBO et al., 2005). Unlike theoretical fractals, which can assume an infinite dimension, fractals found in biological systems have a terminal branching, making it essential to compare the samples in the same scale. The box-counting method is one the of most used methods for estimating the fractal dimension (GRIZZI, RUSSO, COLOMBO et al., 2005; DELGOBO, OTAKE,
SALLES et al., 2011; SMITH, LANGE and MARKS, 1996; FERNANDEZ and JELINEK, 2001), and consists of a grid of boxes of size $e$ superimposed over the image of the structure, as the number of boxes containing any part of the structure is recorded as $N(\boldsymbol{e})$. A fractal object expresses a straight line when $\log [N(\boldsymbol{e})]$ is plotted against $\log (1 / \boldsymbol{e})$. The box fractal dimension (D) can be determined from the slope of the regression line.

\subsection{Processing and image analysis}

The processing and fractal dimension of the images were performed using the Image $J^{\circledR}$ software, available at <http:// rsbweb.nih.gov/ij/> and its extension FracLac, available at <http://rsbweb.nih.gov/ij/plugins/fraclac/fraclac.html>. For analysis of fractal dimension through FracLac, it is necessary to extract and convert an image pattern to a binary system (KARPERIEN, 2007). For more complex structures, the extraction process of the image becomes more robust to ensure that the structures of interest are deployed. For the analysis, it was set a power series of exponential increase of 0.5 for grid caliber, with maximum box size corresponding to $30 \%$ of Region of Interest (ROI) (Figure 1).

\subsection{Statistical analysis}

Data of the fractal dimension are expressed as mean \pm Standard Deviation (SD). Statistical significance was analyzed by Student's t Test with $\mathrm{P}<0.05$ considered significant. Statistical analysis was performed using GraphPad Prism software (San Diego, CA, USA).

\section{Results and Discussion}

The proposed assessment for this article is the contrast between a classical linear approach and nonlinear dynamics.

Classically, the human heart is supported just above the diaphragm, approximately two thirds of the organ is located to the left of the trunk. Its apex is directed forward and downward slightly to the left. The adult human heart has a variation in weight between $250 \mathrm{~g}$ and $310 \mathrm{~g}$, while the adult sheep weighs about $270 \mathrm{~g}$. The difference of mass between the sexes is most marked on human individuals, being the male about $40 \mathrm{~g}$ heavier. Human and sheep hearts showed the same width (front view) of $9.5 \mathrm{~cm}$. The craniocaudal extent of the human heart is about $13 \mathrm{~cm}$ and the sheep $12.5 \mathrm{~cm}$. The side view of the human heart measured $7 \mathrm{~cm}$ and $6 \mathrm{~cm}$ of sheep. Even internally, it is possible to note a remarkable resemblance between the atrial and ventricular chambers and valves.

Table 1 shows some of the principal findings over the linear size comparative between the two species. Interestingly, the myocardium of the sheep evaluated is larger than the human hearts.

\subsection{Comparative analysis of the fractal dimension}

Although by classical anatomical comparison the sheep and human hearts resembles in many features, quantitative analysis of complexity by fractal dimension shows significant differences between their structures (Figures 2, 3). The need for more complex blood flow maintenance of homeostatic functions and the standing position require of the human heart more work compared to sheep heart, justifying differences in structural complexity of the organs in both species (Figure 4). 

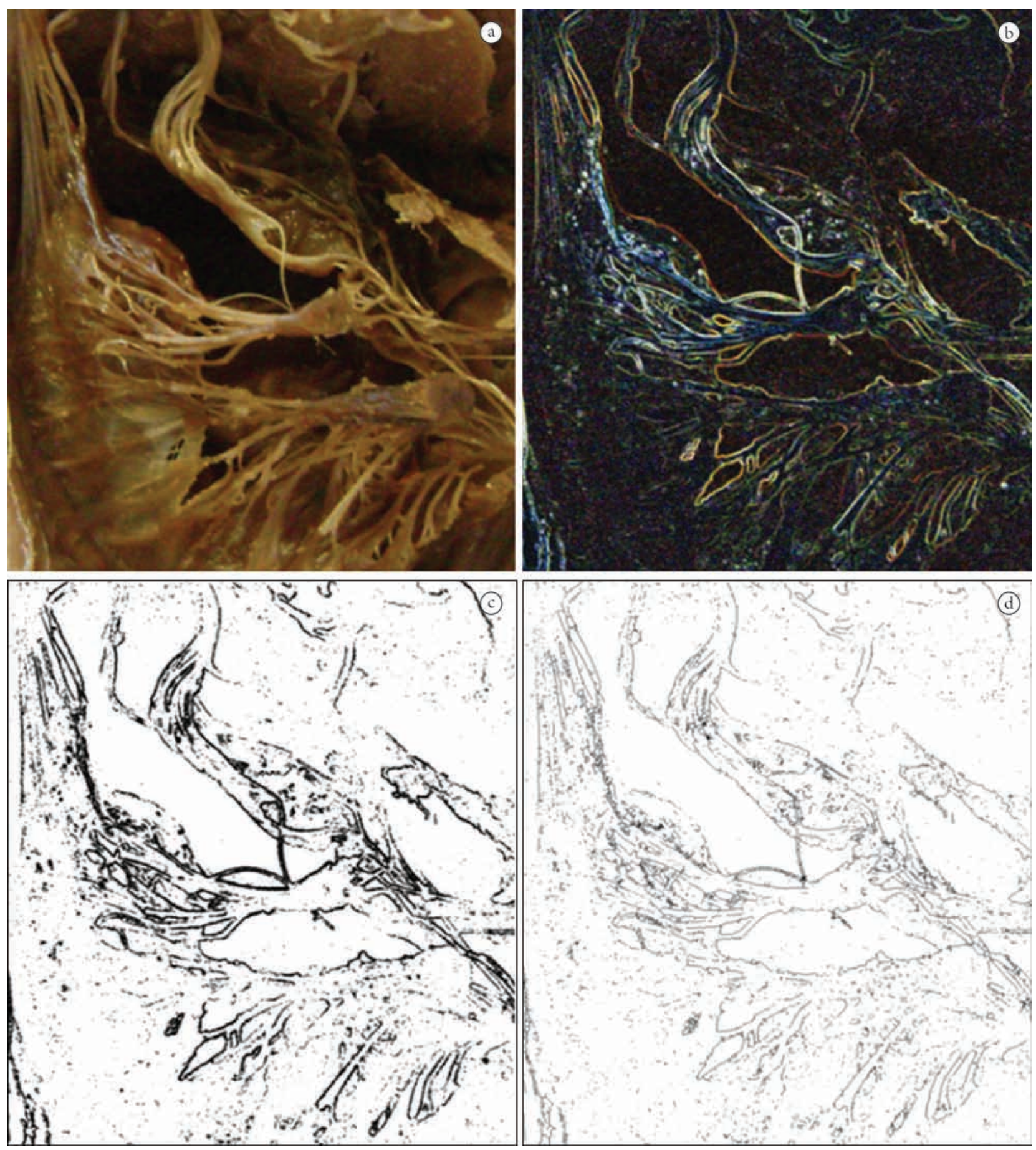

Figure 1. (a) Tricuspid valve of the human heart, unchanged image. (b) Use of the Find Edges tool to highlight branched structures. (c) Use of the tool Make Binary for extracting the binary pattern. (d) Use of the tool Skeletonize, converting groups of pixels of the edge of image in single pixels.

Table 1. Linear evaluation of human against sheep heart. Simple evaluation with digital calipers. Data expressed as mean \pm SD. ${ }^{*} \mathrm{p}<0,05$.

\begin{tabular}{lcccccc}
\hline & $\begin{array}{c}\text { Aortic } \\
\text { Diameter }(\mathbf{m m})\end{array}$ & $\begin{array}{c}\text { Pectinal } \\
\text { Muscles }(\mathbf{m m})\end{array}$ & $\begin{array}{c}\text { Chordae } \\
\text { Tendinae }(\mathbf{m m})\end{array}$ & $\begin{array}{c}\text { Bicuspid } \\
\text { Valve }(\mathbf{m m})\end{array}$ & $\begin{array}{c}\text { Right Ventricle } \\
\text { Myocardium }(\mathbf{m m})\end{array}$ & $\begin{array}{c}\text { Left Ventricle } \\
\text { Myocardium }(\mathbf{m m})\end{array}$ \\
\hline $\begin{array}{l}\text { Human } \\
\text { Heart }\end{array}$ & $20.60( \pm 1.60)$ & $3.88( \pm 0.44)$ & $15.17( \pm 0.30)$ & $19.83( \pm 0.7)$ & $4.853( \pm 1,2)$ & $12( \pm 1.74)$ \\
$\begin{array}{l}\text { Sheep } \\
\text { Heart }\end{array}$ & $20.20( \pm 1.75)$ & $3.34( \pm 0.160)$ & $13.05( \pm 1.00)$ & $21.88( \pm 0.98)$ & $8.474( \pm 0,51)^{*}$ & $23.43( \pm 0.85)^{*}$ \\
\hline
\end{tabular}



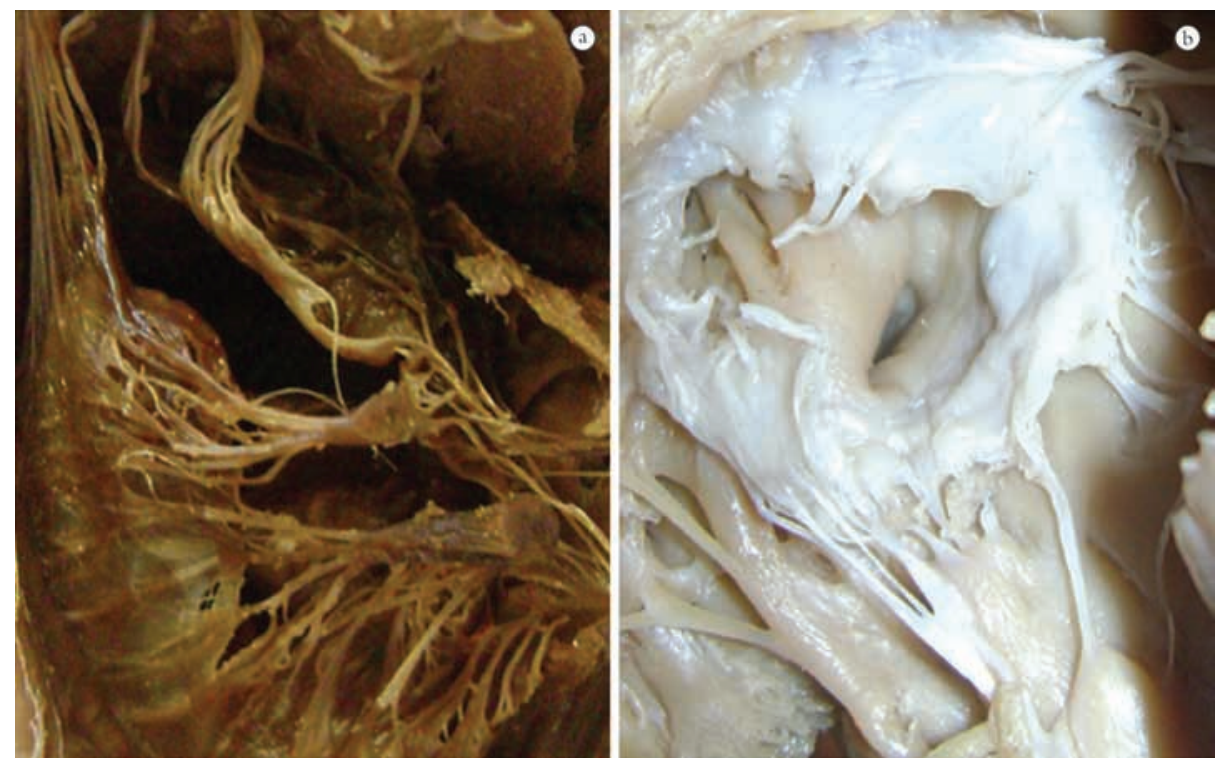

Figure 2. (a) Tricuspid valve of the human heart, mean fractal dimension: 1.868. (b) Tricuspid valve of sheep heart, mean fractal dimension: 1.615. * p: 0,0014.
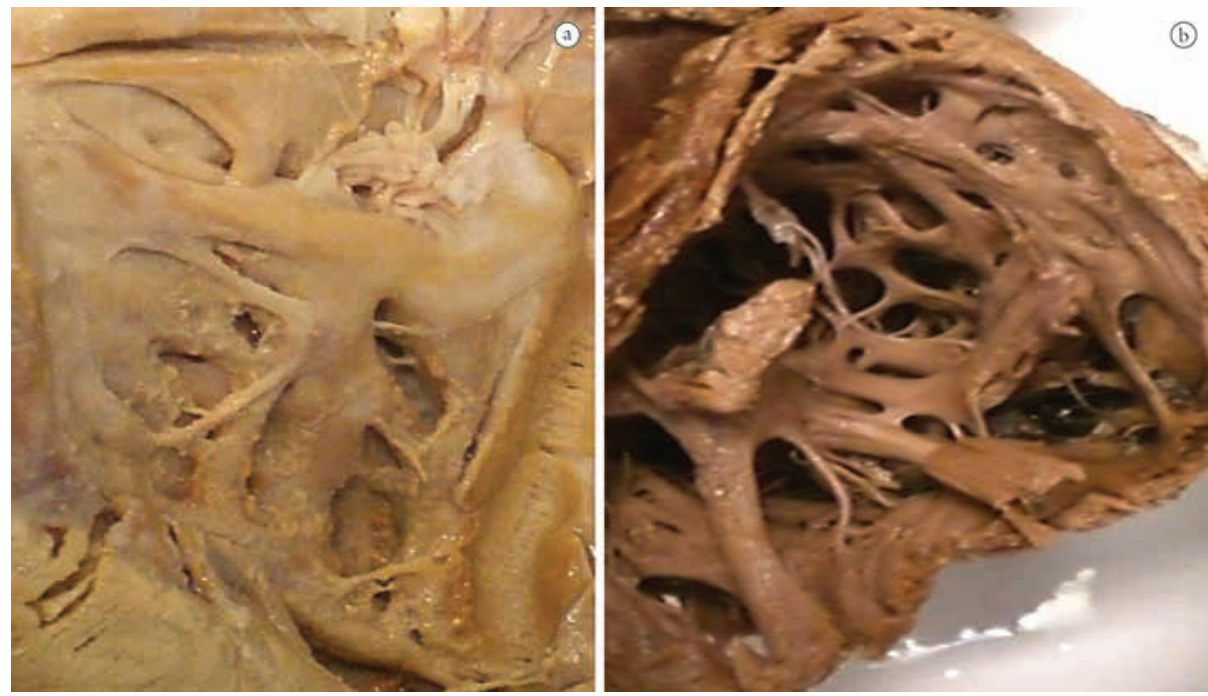

Figure 3. (a) Trabeculae carnea of sheep heart, mean fractal dimension: 1,58. (b) Trabeculae carnea of Human heart, mean fractal dimension: $1,667 .{ }^{*} \mathrm{p}<0,0001$.
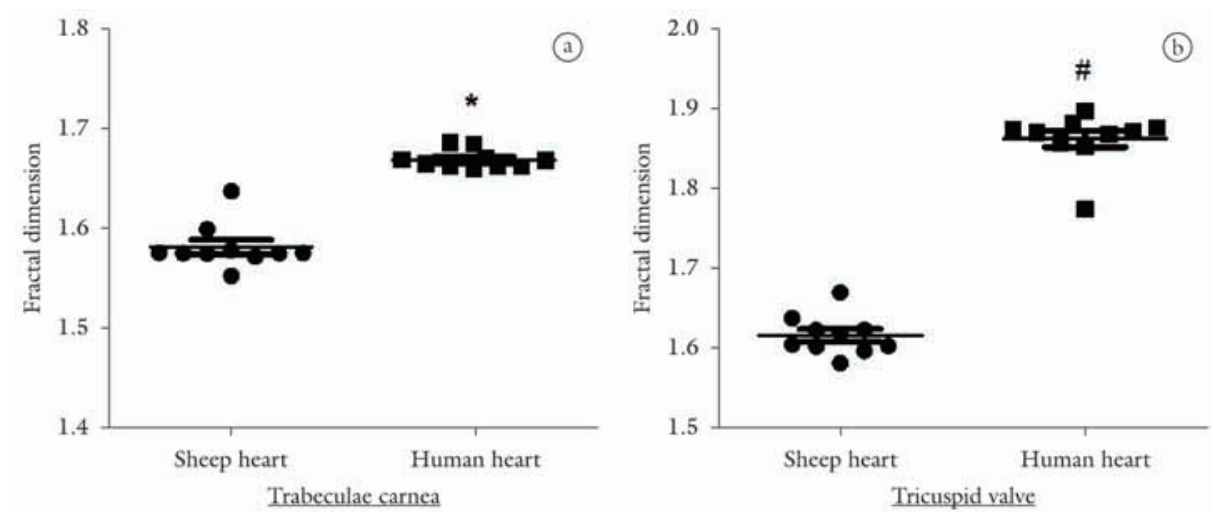

Figure 4. Comparative analysis of fractal dimension on different structures of the human heart and the sheep heart. (a) Fractal dimension of Trabeculae Carnea of sheep and human heart. ${ }^{*} \mathrm{p}<0,01$. (b) Fractal dimension of Tricuspid Valve of sheep and human heart. \# $\mathrm{p}<0,001$. 


\section{Conclusion}

The use of comparative anatomy as an object of study in morphological sciences is universally diffused. The linear evaluation between sheep and human heart show the approximate relative dimensions of size, shape and texture, but the fractal dimension analyzes indicate differences in the morphological complexity of the organ between humankind and sheep. The comparison with linear tool aims to spread the use of the sheep heart as a model for anatomical study, while tools such as nonlinear fractal dimension reinforce an observation of biological systems in a complex, dynamic and adaptive perspective, necessary to a more comprehensive understanding, in our case, of morphological science.

\section{References}

BEHAR, TN. Analysis of fractal dimension of O2A glial cells differentiating in vitro. Methods, 2001, vol. 24, p. 331-339. PMid:11465998. http://dx.doi.org/10.1006/meth.2001.1203

BERNARD, F., BOSSU, JL. and GAILLARD, S. Identification of living oligodendrocyte developmental stages by fractal analysis of cell morphology. Journal of Neurosciences Research, 2001, vol. 65, p. 439-445. PMid:11536328. http://dx.doi.org/10.1002/ jnr.1172

CUTTING, JE. and GARVIN, JJ. Fractal curves, and complexity. Perception \& Psychophysics, 1987, vol. 12, p. 365-370.

DELGOBO, M., OTAKE, A., SALlES, R., BYDLOWSKI, S. and FAVERO, G. Pattern self-repetition allied to complexity and adaptation of different anatomic structures of human body. Journal of Morphological Science, 2011, vol. 28, n. 1, p. 28-34.

FERNANDEZ, E. and JELINEK, HF. Use of fractal theory in neuroscience: Methods, advantages, and potential problems. Methods, 2001, vol. 24, p. 309-321. PMid:11465996. http:// dx.doi.org/10.1006/meth.2001.1201

FUSELER, JW., MILLETTE, CF., DAVIS, JM. and CARVER, W. Fractal and Image Analysis of Morphological Changes in the Actin Cytoskeleton of Neonatal Cardiac Fibroblasts in Response to Mechanical Stretch. Microscopy and Microanalysis, 2007, vol. 13, p. 133-143 PMid:17367553. http://dx.doi.org/10.1017/ S1431927607070225

GRIZZI, F., RUSSO, C., COLOMBO, P., FRANCESCHINI, B., FREZZA, EE., COBOS, E. and CHIRIVA-INTERNATI, M. Quantitative evaluation and modeling of two-dimensional neovascular network complexity: The surface fractal dimension. $B M C$ Cancer, 2005, vol. 5, p. 14-23. PMid:15701176 PMCid:PMC549205. http://dx.doi.org/10.1186/1471-2407-5-14
GUMIERE, SJ., FURLAN, A., SCHWARTZ, D. and GUERRINI, IA. Determinação do expoente de Lyapunov em sequências cardíacas por análises fractais. In: Anais do XXV Congresso Nacional de Matemática Aplicada e Computacional, 2002. Rio de Janeiro: Nova Friburgo, 2002.

JAMES, TN. Morphology of the human atrioventricular node, with remarks pertinent to its electrophysiology. American Heart Journal, 1961, vol. 62, n. 6, p. 756-771. http://dx.doi. org/10.1016/0002-8703(61)90664-0

KARPERIEN, A. FracLacfor ImageJ. Charles Sturt University, 2007.

LORTHOIS, S. and CASSOT, F. Fractal analysis of vascular network: Insights from morphogenesis. Journal of Theoretical Biology, 2010, vol. 262, p. 614-633. PMid:19913557. http:// dx.doi.org/10.1016/j.jtbi.2009.10.037

OLIVEIRA, DJ., GOMES, M., GUIMARÃES, H. and AGUIRRE, L. Síntese de sinais de variabilidade da freqüência cardíaca baseada em modelagem não-linear. Revista Brasileira de Engenharia Biomédica, 2006, vol. 22, n. 1, p. 51-62.

RISTANOVIC, D., NEDELJKOV, V., STEFANOVIC, BD., MILOSEVIC, NT., GRGUREVIC, M. and STULIC, V. Fractal and nonfractal analysis of cell images: Comparison and application to neuronal dendritic arborization. Biological Cybernetics, 2002, vol. 87, p. 278-288. PMid:12386743. http://dx.doi.org/10.1007/ s00422-002-0342-1

SMITH, TG., LANGE, GD. and MARKS, WB. Fractal methods and results in cellular morphology - dimensions, lacunarity and multifractals. Journal of Neuroscience Methods, 1996, vol. 69, p. 123136. http://dx.doi.org/10.1016/S0165-0270(96)00080-5

TULPPO, MP., KIVINIEMI, AM., HAUTALA, AJ., KALLIO, M., SEPPANEM, T., MAKIKALLIO, T. and HUIKURI, HV. Physiological Background of the Loss of Fractal Heart Rate Dynamics. Journal of the American Heart Association, 2005, vol. 112, p. 314-319.

ZHANG, L., LIU, JZ., DEAN, D., SAHGAL, V. and YUE, GH. A three dimensional fractal analysis method for quantifying white matter structure in human brain. Journal of Neurosciences Methods, 2005, vol. 150, p. 242-253. PMid:16112737. http:// dx.doi.org/10.1016/j.jneumeth.2005.06.021 